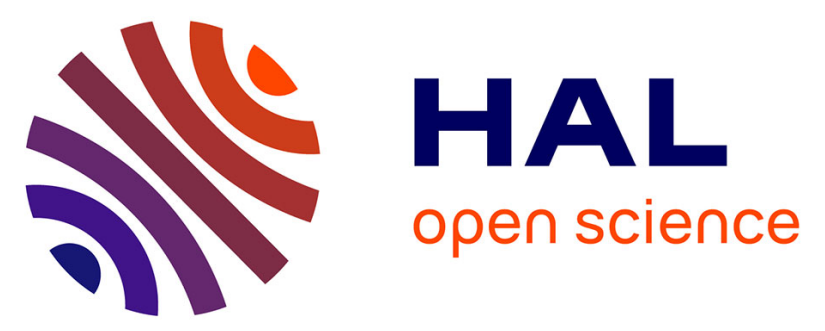

\title{
Donor-substituted triaryl-1,3,5-triazinanes-2,4,6-triones: octupolar NLO-phores with a remarkable transparency-nonlinearity trade-off
}

Gilles Argouarch, Romain Veillard, Thierry Roisnel, Anissa Amar, Abdou Boucekkine, Anu Singh, Isabelle Ledoux, Frédéric Paul

\section{To cite this version:}

Gilles Argouarch, Romain Veillard, Thierry Roisnel, Anissa Amar, Abdou Boucekkine, et al.. Donor-substituted triaryl-1,3,5-triazinanes-2,4,6-triones: octupolar NLO-phores with a remarkable transparency-nonlinearity trade-off. New Journal of Chemistry, 2011, 35 (11), pp.2409-2411. 10.1039/C1NJ20442D . hal-00735209

\section{HAL Id: hal-00735209 \\ https://hal.science/hal-00735209}

Submitted on 10 Sep 2013

HAL is a multi-disciplinary open access archive for the deposit and dissemination of scientific research documents, whether they are published or not. The documents may come from teaching and research institutions in France or abroad, or from public or private research centers.
L'archive ouverte pluridisciplinaire HAL, est destinée au dépôt et à la diffusion de documents scientifiques de niveau recherche, publiés ou non, émanant des établissements d'enseignement et de recherche français ou étrangers, des laboratoires publics ou privés. 


\title{
Donor-substituted triaryl-1,3,5-triazinanes-2,4,6-triones: octupolar NLO-phores with a remarkable transparency-nonlinearity trade-off $\dagger$
}

\author{
Gilles Argouarch, ${ }^{a}$ Romain Veillard, ${ }^{a}$ Thierry Roisnel, ${ }^{a}$ Anissa Amar, ${ }^{a}$ \\ Abdou Boucekkine, ${ }^{a}$ Anu Singh, ${ }^{b}$ Isabelle Ledoux ${ }^{* b}$ and Frédéric Paul ${ }^{* a}$ \\ Received (in Montpellier, France) 25th May 2011, Accepted 12th July 2011 \\ DOI: $10.1039 / \mathrm{c} 1 \mathrm{nj} 20442 \mathrm{~d}$
}

We report in this letter the measurement of the hyperpolarizabilities of a series of donor-substituted triaryl-1,3,5-triazinanes2,4,6-triones by hyper Rayleigh scattering (HRS). A remarkable transparency-nonlinearity trade-off is evidenced for these octupolar NLO-phores which might be accessed in a straightforward synthetic way and in a few steps from commercial isocyanates.

Since the 1980's, molecules with nonlinear optical (NLO) properties have attracted increasing interest in the telecommunications and signal processing domains. This interest is mostly driven by the very promising applications expected from materials made of such units, such as ultradense optical data storage or ultrafast information processing. ${ }^{1}$

Among these, octupolar chromophores have attracted a particular attention subsequent to the seminal work of Zyss and coworkers. ${ }^{2-4}$ Indeed, the lack of permanent dipole moment of octupolar structures, usually associated with an improved hyperpolarizability and with a good transparency, constitutes a strong advantage over more classic dipolar structures for many applications. ${ }^{5}$

However, while systematic investigations regarding the second-order NLO properties of various kinds of molecules of $D_{3}$ or $D_{3 \mathrm{~h}}$ symmetry have been conducted, ${ }^{6-11}$ triazinane2,4,6-triones (Scheme 1; A), more commonly known as isocyanurates, have only attracted a limited attention up to now. ${ }^{12}$

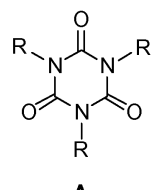

A

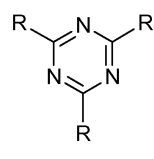

B

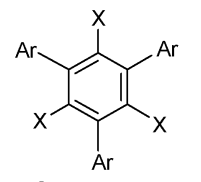

C $(\mathrm{X}=\mathrm{CN}, \mathrm{OMe})$
Scheme 1

\footnotetext{
${ }^{a}$ Sciences Chimiques de Rennes, UMR CNRS 6226, Université de Rennes 1, Campus de Beaulieu, 35042 Rennes Cedex, France.

E-mail: frederic.paul@univ-rennes1.fr

${ }^{b}$ Laboratoire de Photonique Quantique et Moléculaire, UMR CNRS 8537, ENS Cachan, 61 Avenue du Président Wilson, F-94235 Cachan Cedex, France

$\dagger$ Electronic supplementary information (ESI) available: Details on the procedure used for the NLO measurements. CCDC reference number 826557 (4). For ESI and crystallographic data in CIF or other electronic format see DOI: $10.1039 / \mathrm{c} 1 \mathrm{nj} 20442 \mathrm{~d}$
}

Considering their structural similarity with more widely studied octupoles such as triazines (B) or 1,3,5-triarylphenylene-based molecules $(\mathrm{C}),{ }^{13}$ we expected that these molecules could exhibit sizable hyperpolarizabilities, especially if their electron-deficient core could be substituted with electron-releasing arms. We therefore decided to synthesize and investigate the NLO properties of derivatives such as $\mathbf{1 - X}$ and $\mathbf{2}-\mathbf{X}$ or $\mathbf{3}$ by hyper Raleigh scattering (HRS) (Scheme 2).

The shorter representatives $\mathbf{1}-\mathbf{X}\left(\mathrm{X}=\mathrm{OMe}, \mathrm{NMe}_{2}, \mathrm{Br}\right)$ were accessed in a single step directly from the commercial isocyanates, while the longer ones were obtained in one additional step from $\mathbf{1}-\mathbf{B r}$ and the corresponding alkynes using a simple Sonogashira coupling protocol (Scheme 3). ${ }^{14}$

These derivatives were characterized by mass spectrometry and usual spectroscopies. The crystal structure of the terminal triyne derivative $\mathbf{4}(\mathrm{R}=\mathrm{H})$ could also be solved (Fig. 1). This compound was isolated after de-silylation of its silylated precursor $4^{\prime}\left(\mathrm{R}=\mathrm{SiMe}_{3}\right)$, which was itself obtained similarly to $\mathbf{2}-\mathbf{X}$ or $\mathbf{3}$ using ethynyltrimethylsilane. This crystal structure confirmed the octupolar symmetry of this new family of alkynylfunctionalized cyclotrimers and provided useful geometrical data for theoretical modelling of these compounds by DFT.

The UV-vis absorption spectra of these compounds were recorded in dichloromethane (Table 1). In line with their colorless nature, $\mathbf{1}-\mathbf{X}$ and $\mathbf{2}-\mathbf{X}$ present a broad transparency range in the near-UV/visible region, their absorption at lowest energy lying below $300 \mathrm{~nm}$ for the shorter derivatives 1-X.

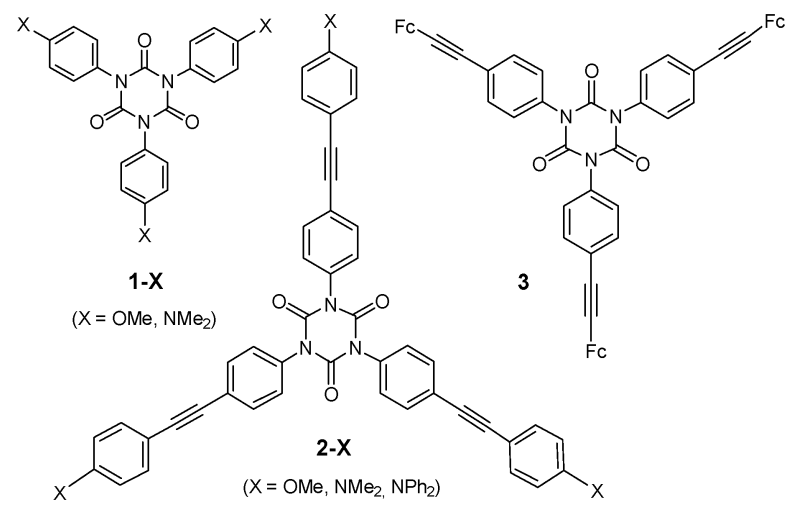

Scheme 2 


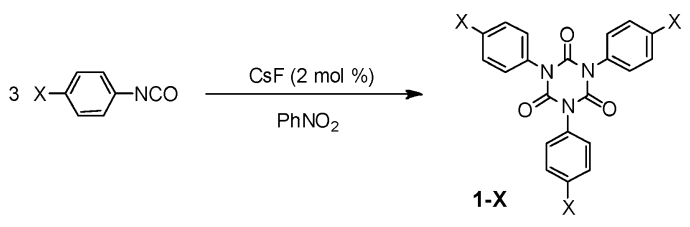

$\left(88 \%, \mathrm{X}=\mathrm{Br} ; 73 \%, \mathrm{X}=\mathrm{OMe} ; 70 \%, \mathrm{X}=\mathrm{NMe}_{2}\right)$

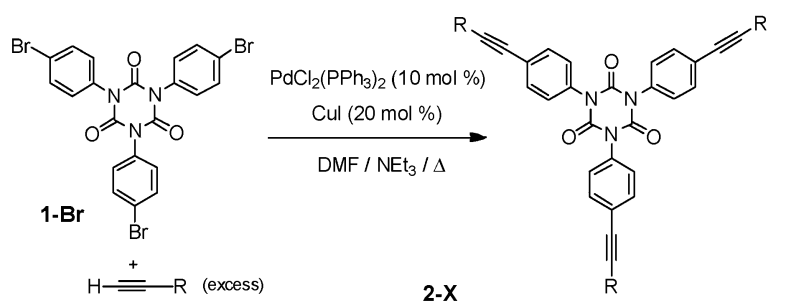

$\left(82 \%, \mathrm{R}=4-\mathrm{C}_{6} \mathrm{H}_{4} \mathrm{OMe} ; 50 \%, \mathrm{R}=4-\mathrm{C}_{6} \mathrm{H}_{4} \mathrm{NMe}_{2} ; 61 \%, \mathrm{R}=4-\mathrm{C}_{6} \mathrm{H}_{4} \mathrm{NPh}_{2}\right)$

$3(42 \%, \mathrm{R}=\mathrm{Fc})$

Scheme 3

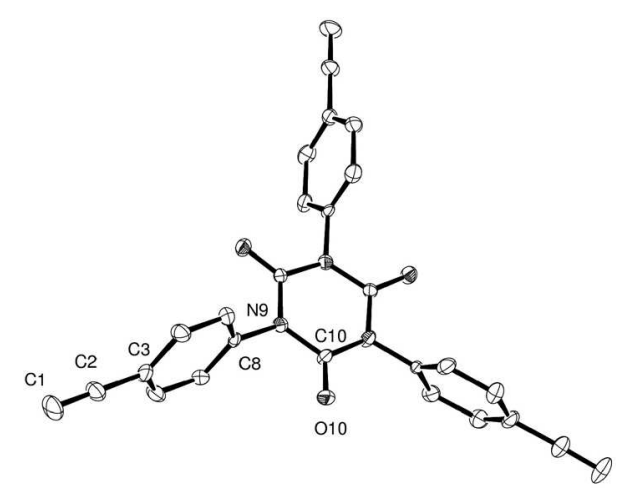

Fig. 1 ORTEP of $4(50 \%$ probability level, one molecule of the asymmetric unit). Hydrogen atoms have been omitted for clarity. Selected bond lengths $(\AA)$ and angles $\left({ }^{\circ}\right)$ : $\mathrm{C} 1-\mathrm{C} 2$ : 1.203(6); C2-C3: 1.450(6); C8-N9: 1.460(5); N9-C10: 1.398(3); C10-O10: 1.206(5); N9-C10-O10: 122.0(3); C10-N9-C10': 123.8(4); N9-C10-N9': 115.9(4).

Table 1 Molecular hyperpolarizabilities and related data experimentally derived for these octupolar compounds in $\mathrm{CH}_{2} \mathrm{Cl}_{2}(1.907 \mu \mathrm{m})$ or in $\mathrm{CHCl}_{3}(1.067 \mu \mathrm{m})$

\begin{tabular}{llccc}
\hline Compound & $\lambda_{\max }{ }^{a}$ & $\varepsilon_{\max }{ }^{b}$ & $\beta_{\mathrm{HRS}}{ }^{c}$ & $\beta_{\mathrm{HRS}}(0)^{c, d}$ \\
\hline 1-OMe & 228 & 60.5 & $19^{e}$ & $15^{e}$ \\
1-NMe $_{2}$ & 270 & 58.2 & 55 & 50 \\
2-OMe & 316 & 104.4 & $32^{e}$ & $19^{e}$ \\
${\mathbf{2}-\mathbf{N M e}_{2}}_{\mathbf{2}-\mathbf{N P h}_{2}}^{352}$ & 109.6 & 66 & 55 \\
$\mathbf{3}$ & 362 & 99.0 & 78 & 64 \\
& 342 & 11.4 & $49^{e}$ & $26^{e}$
\end{tabular}

${ }^{a}$ In nm. ${ }^{b}$ In $10^{3} \mathrm{M}^{-1} \mathrm{~cm}^{-1} \cdot{ }^{c}$ In $10^{-30}$ esu (correlation between SI units: $\left.\beta(\mathrm{SI})=4.172 \times 10^{-10} \beta(\mathrm{esu})\right)$. The precision of the measurements is about $\pm 15 \%$. The reported $\beta$ values are given in the $\beta^{\mathrm{X}}$ convention as defined by Willetts et al. ${ }^{15 d}$ Calculated from UV data using the dispersion factor corresponding to a degenerate three level model with $\lambda_{0}=1.06 \mu \mathrm{m} .{ }^{4}{ }^{e}$ Measurement performed in chloroform.

As expected, this absorption is bathochromically shifted when the para-substituents become electron-releasing and when the unsaturated arm is extended, i.e. when progressing from 1-X to $\mathbf{2}-\mathbf{X}$. Among the shorter derivatives, a further
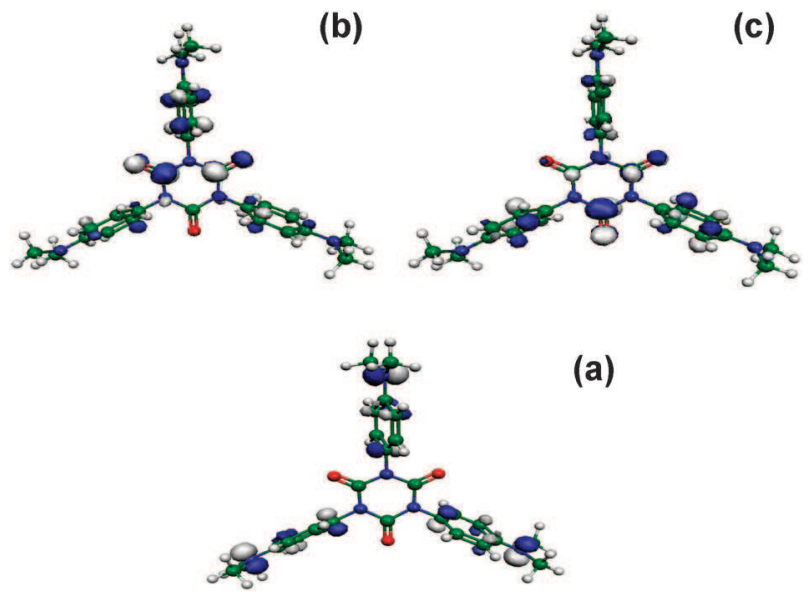

(a)

Fig. 2 Contour surfaces of HOMO (a) and degenerated LUMO, LUMO $+1(b-c)$ of the cyclotrimer $\mathbf{1}-\mathbf{N M e}_{2}$.

bathochromic shift is observed for $\mathbf{3}$ which appears slightly coloured in solution, due to a low intensity absorption extending towards the visible range.

DFT calculations reveal that the observed absorptions can be attributed to symmetry allowed transitions corresponding to a charge shift from peripheral arms towards the central isocyanurate ring (Fig. 2). These transitions were computed at $220 \mathrm{~nm}$ for 1-OMe, $250 \mathrm{~nm}$ for 1-NMe $\mathbf{2}, 333 \mathrm{~nm}$ for 2-OMe, $375 \mathrm{~nm}$ for $\mathbf{2}-\mathbf{N M e}_{\mathbf{2}}$ and $404 \mathrm{~nm}$ for $\mathbf{2}-\mathbf{N P h}_{\mathbf{2}}$ in $\mathbf{C H}_{2} \mathrm{Cl}_{2}$, respectively, i.e. in fair agreement with the experiment.

The hyperpolarizabilities of these compounds were subsequently measured in dichloromethane or chloroform using HRS with an incident laser beam at $1907 \mathrm{~nm}$ or $1067 \mathrm{~nm}$ (Table 1). The corresponding static hyperpolarizability values $\beta_{\text {HRS }}(0)$ were also derived. ${ }^{4,16,17}$ Among the organic compounds $\mathbf{1}-\mathbf{X}$ and $\mathbf{2}-\mathbf{X}$, increasing the donating strength of the substituents or the length of the bridge results in an enhancement of $\beta_{\mathrm{HRS}}$, which is partly attributable to dispersion factors, according to the corresponding $\beta_{\mathrm{HRS}}(0)$ values. The electronic effect of the $\mathrm{X}$ substituent on $\beta_{\mathrm{HRS}}(0)$ values appears predominant over the bridge elongation. Notably, a sizable improvement is stated for $\mathbf{3}$ over 1-OMe, albeit a smaller electron-releasing power is attributed to the $\mathrm{C} \equiv \mathrm{C}-\mathrm{Fc}$ substituent when compared to a methoxy group, based on electronic substituent parameters. ${ }^{18}$ This suggests that the more "polarizable" nature of this organometallic substituent is also beneficial to the second-order NLO activity.

Comparison with $\beta_{\mathrm{HRS}}$ values reported for related octupoles ${ }^{13}$ indicates that the values obtained for the derivatives 1-X $\left(\mathrm{X}=\mathrm{OMe}, \mathrm{NMe}_{2}\right)$ and $\mathbf{2 - X}\left(\mathrm{X}=\mathrm{OMe}, \mathrm{NMe}_{2}, \mathrm{NPh}_{2}\right)$ are far from being negligible. First, as expected, these derivatives present a much better hyperpolarizability than the few previously examined isocyanurate derivatives featuring electron-poorer arms and for which no conjugation was effective with the central core. ${ }^{12}$ Then, in terms of NLOactivity, the shorter derivatives (1-X) compare with those reported for donor-substituted triaryl triazines $(\mathrm{B} ; \mathrm{R}=\mathrm{Ar}$; Scheme 1), ${ }^{10,19}$ while the longer ones (2-X; X $=\mathrm{OMe}, \mathrm{NMe}_{2}$, $\mathrm{NPh}_{2}$ ) compare with those of triphenylaryl-based chromophores of same size and close constitution. ${ }^{9}$ However, in both cases, the low-energy absorption $\left(\lambda_{\max }\right)$ of $\mathbf{1 - X}$ and $\mathbf{2}-\mathbf{X}$ is 
blue-shifted by at least $30 \mathrm{~nm}$. Actually, in terms of transparencyactivity trade-off, the shorter octupoles $\mathbf{1}-\mathbf{X}$ present performances comparable to boroxine-based derivatives, also previously studied by one of us. ${ }^{20-22}$

In conclusion, the organic derivatives $\mathbf{1}-\mathbf{X}$ and $\mathbf{2}-\mathbf{X}$, straightforwardly accessible from commercial reactants, present a remarkable efficiency-transparency trade-off when compared to most octupolar derivatives studied so far. For instance, most of them display $\beta_{\mathrm{DFT}}(0)$ values significantly larger than the prototypical TIATB,$^{20,23}$ while remaining blue-shifted by nearly $100 \mathrm{~nm}$, at least for the shorter derivatives $\mathbf{1}-\mathbf{X}$. In addition, this study reveals that a change of the terminal electron-releasing group apparently produces a stronger effect than extending the conjugation path with the isocyanurate core. In this connection, replacement of the alkynylferrocenyl donor groups in $\mathbf{3}$ by more electron-releasing organometallics might provide a simple means to increase further the hyperpolarizability of these compounds, while maintaining a fair transparency. Work along these lines is in progress.

\section{Experimental}

The reactions were carried out under an inert atmosphere using the Schlenk techniques. Solvents were freshly distilled under argon using standard procedures.

\section{1,3,5-Tris(4-ethynylphenyl)-1,3,5-triazinane-2,4,6 trione (4)}

In an oven-dried Schlenk tube, to a mixture of $\mathbf{1}-\mathbf{B r}^{14}$ (2 g; $3.37 \mathrm{mmol}), \mathrm{CuI}(0.128 \mathrm{~g} ; 0.67 \mathrm{mmol}, 20 \mathrm{~mol} \%), \mathrm{PdCl}_{2}\left(\mathrm{PPh}_{3}\right)_{2}$ $(0.236 \mathrm{~g} ; 0.34 \mathrm{mmol}, 10 \mathrm{~mol} \%)$ in a DMF-Et ${ }_{3} \mathrm{~N}$ (5:1) mixture $(60 \mathrm{~mL})$ was added an excess of trimethylsilylacetylene $(2.90 \mathrm{~mL}, 20.20 \mathrm{mmol})$. After 2 days of stirring at $70{ }^{\circ} \mathrm{C}$ and cooling to room temperature, the solvents were removed by cryoscopic transfer. The reaction mixture was extracted with $\mathrm{CH}_{2} \mathrm{Cl}_{2}$, washed with water and dried over $\mathrm{MgSO}_{4}$. After filtration and evaporation to dryness, the crude product was purified by column chromatography on silica gel (hexane/ $\left.\mathrm{Et}_{2} \mathrm{O}, 1: 1\right)$, providing $\mathbf{4}^{\prime}$ as a pale solid $(1.37 \mathrm{~g} ; 2.12 \mathrm{mmol}$; $63 \%)$. A solution of this compound $\left(4^{\prime} ; 820 \mathrm{mg}, 1.27 \mathrm{mmol}\right)$ and TBAF $(0.38 \mathrm{~mL}, 1 \mathrm{M}$ solution in THF, $0.38 \mathrm{mmol})$ in THF $(30 \mathrm{~mL})$ was shielded from light and stirred overnight at room temperature. After evacuation of the solvent, the reaction mixture was extracted with $\mathrm{CH}_{2} \mathrm{Cl}_{2}$, washed with water and dried over $\mathrm{MgSO}_{4}$. After filtration and evaporation to dryness, the crude product was purified by column chromatography on silica gel with $\mathrm{CH}_{2} \mathrm{Cl}_{2}$ to yield $\mathbf{4}$ as a pale solid (300 mg; 55\%). HRMS (EI) $m / z \quad 429.1105$ (calc. for $\mathrm{C}_{27} \mathrm{H}_{15} \mathrm{~N}_{3} \mathrm{O}_{3}$ : 429.1113). FT-IR (v, $\left.\mathrm{KBr}, \mathrm{cm}^{-1}\right)$ : $1705(\mathrm{C}=\mathrm{O}$, vs.), 2110 (C $\equiv \mathrm{C}, w), 3275$ ( $\equiv \mathrm{C}-\mathrm{H}, v s$.). ${ }^{1} \mathrm{H}$ NMR (200 MHz, $\mathrm{CD}_{2} \mathrm{Cl}_{2}, \delta$ in ppm): $7.69\left(\mathrm{~d}, 6 \mathrm{H},{ }^{3} J_{\mathrm{H}, \mathrm{H}}=8.4 \mathrm{~Hz}\right), 7.42(\mathrm{~d}, 6 \mathrm{H}$, $\left.{ }^{3} J_{\mathrm{H}, \mathrm{H}}=8.4 \mathrm{~Hz}\right), 3.29(\mathrm{~s}, 3 \mathrm{H}) \cdot{ }^{13} \mathrm{C}\left\{{ }^{1} \mathrm{H}\right\} \mathrm{NMR}(50 \mathrm{MHz}$, $\mathrm{CD}_{2} \mathrm{Cl}_{2}, \delta$ in ppm): $148.5,134.2,133.5,129.0,123.9,82.5$, 79.1. X-Ray-quality crystals were grown by slow diffusion of pentane into a $\mathrm{CH}_{2} \mathrm{Cl}_{2}$ solution of 4 .

\section{X-Ray crystallography}

Diffraction data frames for 4 were collected on a APEXII, Bruker-AXS diffractometer at 100(2) K using the Mo-K $\alpha$ radiation $(\lambda=0.71073 \AA)$. The structure was solved by direct methods using the SIR97 program, ${ }^{24}$ and then refined with full-matrix least-square methods based on $\mathrm{F}^{2}$ (SHELX-97) ${ }^{25}$ with the aid of the WINGX ${ }^{26}$ program. All non-hydrogen atoms were refined with anisotropic thermal parameters. $\mathrm{H}$ atoms were finally included in their calculated positions. A final refinement on $\mathrm{F}^{2}$ with 1002 unique intensities and 100 parameters converged at $\mathrm{w} R\left(F^{2}\right)=0.1716(R(F)=0.0693)$ for 967 observed reflections with $I>2 \sigma(I)$. Crystal data: $\mathrm{C}_{27} \mathrm{H}_{15} \mathrm{~N}_{3} \mathrm{O}_{3}, \quad M=429.42$, trigonal, space group $R 3 c$, $a=13.5264(13) \AA, b=13.526 \AA, c=24.608(2) \AA$, $\alpha=90^{\circ}, \beta=90^{\circ}, \gamma=120^{\circ}, U=3899.2(5) \AA^{3}, Z=6$, $T=100(2) \mathrm{K}, D_{\mathrm{c}}=1.097 \mathrm{~g} \mathrm{~cm}^{-3}, 7587$ reflections measured, 1002 unique $\left(R_{\text {int }}=0.0576\right)$ which were used in calculations. The final w $R\left(F^{2}\right)$ was 0.1732 (all data). CCDC 826557.

\section{Acknowledgements}

CNRS is acknowledged for specific financial supports.

\section{Notes and references}

1 S. R. Marder, Chem. Commun., 2006, 131-134.

2 O. Maury and H. Le Bozec, Acc. Chem. Res., 2005, 38, 691-703.

3 J. J. Wolff and R. Wortmann, J. Prakt. Chem., 1998, 340, 99-111.

4 J. Zyss and I. Ledoux, Chem. Rev., 1994, 94, 77-105.

5 J. Zyss, Nonlinear Opt., 1991, 1, 3-18.

6 S.-H. Lee, J.-R. Park, M.-Y. Jeong, H. M. Kim, S. Li, J. Song, S. Ham, S.-J. Jeon and B. R. Cho, ChemPhysChem, 2006, 7, 206-212.

7 M. J. Piao, K. Chajara, S. J. Yoon, H. M. Kim, S.-J. Jeon, H. M. Kim, K. Song, I. Asselberghs, A. Persoons, K. Clays and B. R. Cho, J. Mater. Chem., 2006, 16, 2273-2281.

8 B. Traber, J. J. Wolff, F. Rominger, T. Oeser, R. Gleiter, M. Goebel and R. Wortmann, Chem.-Eur. J., 2004, 10, 1227-1238.

9 J. Brunel, O. Mongin, A. Jutand, I. Ledoux, J. Zyss and M. Blanchard-Desce, Chem. Mater., 2003, 15, 4139-4148.

10 J. J. Wolff, F. Siegler, R. Matschiner and R. Wortmann, Angew. Chem., Int. Ed., 2000, 39, 1436-1439.

11 R. Wortmann, C. Glania, P. Krämer, R. Matschiner, J. J. Wolff, S. Kraft, B. Treptow, E. Barbu, D. Längle and G. Görlitz, Chem.-Eur. J., 1997, 3, 1765-1773.

12 V. R. Thalladi, S. Brasselet, D. Bläser, R. Boese, J. Zyss, A. Nangia and G. R. Desiraju, Chem. Commun., 1997, 1841-1842.

13 H. M. Kim and B. R. Cho, J. Mater. Chem., 2009, 19, 7402-7409.

14 F. Paul et al., to be published, see also: Y. Nambu and T. Endo, J. Org. Chem., 1993, 58, 1932-1934.

15 A. Willetts, J. E. Rice, D. M. Burland and D. P. Shelton, J. Chem. Phys., 1992, 97, 7590-7599.

16 J. D. Weibel, D. Yaron and J. Zyss, J. Chem. Phys., 2003, 119, 11847-11863.

17 E. Hendrickx, K. Clays and A. Persoons, Acc. Chem. Res., 1998, 31, 675-683.

18 C. Hansch, A. Leo and R. W. Taft, Chem. Rev., 1991, 91, 165-195.

19 S. Brasselet, F. Cherioux, P. Audebert and J. Zyss, Chem. Mater., 1999, 11, 1915-1920.

20 G. Alcaraz, L. Euzenat, O. Mongin, C. Katan, I. Ledoux, J. Zyss, M. Blanchard-Desce and M. Vaultier, Chem. Commun., 2003, 2766-2767.

21 F. Ibersiene, D. Hammoutène, A. Boucekkine, C. Katan and M. Blanchard-Desce, THEOCHEM, 2008, 866, 58-62.

22 C. Katan, O. Mongin, G. Alcaraz, M. Vaultier, A. Boucekkine and M. Blanchard-Desce, Proc. SPIE-Int. Soc. Opt. Eng., 2004, 26, 5517-5528.

23 T. Verbiest, K. Clays, C. Samyn, J. Wolff, D. Reinhoudt and A. Persoons, J. Am. Chem. Soc., 1994, 116, 9320-9323.

24 A. Altomare, M. C. Burla, M. Camalli, G. Cascarano, C. Giacovazzo, A. Guagliardi, A. G. G. Moliterni, G. Polidori and R. Spagna, J. Appl. Crystallogr., 1999, 32, 115-119.

25 G. M. Sheldrick, SHELX97-2. Program for the refinement of crystal structures, Univ. of Göttingen, Germany, 1997.

26 L. J. Farrugia, J. Appl. Crystallogr., 1999, 32, 837-838. 